\title{
Do We Need Partial Intentions?
}

\author{
Avery Archer
}

\begin{abstract}
Richard Holton has argued that the traditional account of intentions - which only posits the existence of all-out intentions - is inadequate because it fails to accommodate dual-plan cases; ones in which it is rationally permissible for an agent to adopt two competing plans to bring about the same end. Since the consistency norms governing all-out intentions prohibit the adoption of competing intentions, we can only preserve the idea that the agent in a dual-plan case is not being irrational if we attribute to them a pair of partial intentions. I argue that, contrary to initial appearances, (i) Holton has yet to offer us an actual account of partial intentions, and (ii) that the traditional account of intentions already has the resources necessary to accommodate dualplan cases.
\end{abstract}

Keywords: Partial intention - Intending to try $\bullet$ Means-end coherence • Practical Reason • Richard Holton

\section{Introduction}

In his paper, "Partial Belief, Partial Intention," Richard Holton argues that we must posit the existence of partial intentions in order to make sense of certain kinds of cases; namely, ones in which an agent's uncertainty about achieving an end in one way prompts her to form a second, mutually exclusive, back-up plan for achieving the same end in some other way. Let us call such cases dual-plan cases. According to Holton, dual-plan cases reveal that the traditional account of intention-which only posits the existence of all-out intentions - is inadequate. This is because the consistency norms governing all-out intentions prohibits the adoption of competing (i.e., mutually exclusive) intentions. However, the agent in a dual-plan case is not being irrational. Moreover, by Holton's lights, we can only make sense of why the agent in a dual-plan case is not being irrational if we attribute to them a partial intention.

In this paper, I advance two separate lines of argument against Holton's conclusion. First, I argue that, contrary to initial appearances, Holton has not yet offered us an account of partial intentions. This is not so much a criticism of the notion of partial intentions per se as it is the claim that there is no account of partial intentions on offer in Holton's paper. This is surprising since Holton takes himself to be offering just such an account. Second, I argue that the traditional account of intention (i.e., one that does not include partial intentions) has the resources necessary to deal with dualplan cases. Hence, even if an account of partial intentions could be given at some point in the future, Holton would have failed to show that there is a need for such an account. 
I begin my investigation by considering three proposals for analysing dual-plan cases-what I refer to as (i) the all-out intention analysis, (ii) the disjunctive intention analysis, and (iii) the conditional intention analysis. I argue that all three fail to meet Holton's challenge. I will then turn my attention to the partial intention analysis (which is my name for Holton's account). I argue that, contrary to initial appearances, Holton has not really given us an account of partial intentions. Finally, I put forward my own analysis - the intending to try analysis - and argue that it has the resources necessary to meet Holton's challenge. If my argument succeeds, it would follow that the traditional account of intention already has the resources necessary to accommodate dual-plan cases; there is therefore no need to posit the existence of partial intentions to handle such cases.

\section{The All-Out Intention Analysis}

Holton gives the following example of what I have been calling a dual-plan case ${ }^{1}$ :

\section{OVERDUE BOOKS}

You have some library books that are badly overdue; in fact so badly overdue that your borrowing privileges are about to be suspended (a major inconvenience) if you do not return or renew them by the end of the day. Since you have finished with them, the best thing would be to drop them off at the library on your way home; but that is after the departmental seminar, and you know that, once you get on your bike with your head full of ideas from the discussion, you are all too likely to cycle straight home. Alternatively, you could renew them online; but that would require your library password, which is scribbled on a piece of paper lying somewhere on your desk at home. If you renewed them online you would not need to take the books home with you, but you would need to take your laptop, which you would otherwise leave at work. In the end you head for the seminar with your bag weighed down by both the library books and your laptop, moved by the thought that you will avoid suspension one way or another. ${ }^{2}$

One distinctive feature of OVERDUE BOOKS is that it seems as though it would be irrational for the agent described in the example (let us call him Richard) to deliberately refrain from packing the books and laptop, given his dual plans. This is a wide scope requirement. Richard is rationally required to pack the books and his laptop so long as he continues to have the dual plans of returning and renewing the books. He may discharge this requirement by either adopting the intention to pack the books and laptop, or by giving up on one or both of his plans. However, should he

\footnotetext{
${ }^{1}$ Among action theorists, the expression "plan" is a term of art, with various technical meanings and

${ }^{2}$ Holton (2008: 28-29).
} 
continue to have the plan to return the books and the (backup) plan to renew the books online, it seems as though it would be irrational for Richard to decide not to pack his books and laptop.

Admittedly, we can imagine a scenario in which Richard, after reflecting on his tendency to forget to do things after department talks, simply decides to give up on the plan of returning the books and settles on the plan of renewing the books. So described, it would not be rationally required that Richard pack the books in his bag. But describing Richard in this way would be to change Holton's example. As described by Holton, Richard does in fact plan to return the books. Given this plan, it would be irrational for Richard to decide not to pack the books. The point also applies to Richard's decision to pack his laptop. It would be irrational for Richard to decide not to pack his laptop, so long as he has the (backup) plan of renewing the books online. In short, so long as Richard has the plan to return the books and the (backup) plan to renew the books online, it would be irrational for him not to pack both his books and laptop. If an account of dual-plan cases is going to be satisfactory, it must preserve this idea.

One way we may attempt to make sense of OVERDUE BOOKS is by claiming that Richard has an all-out intention to return the books and an all-out intention to renew the books, where an all-out intention is simply the standard kind of intention discussed in the action theory literature. Call this the all-out intention analysis. The main strength of the all-out intention analysis is that it explains why Richard is rationally required to pack both the books and the laptop, so long as he continues to have the dual plans of returning and renewing the books. ${ }^{3}$ Simply put, by adopting a pair of all-out intentions, Richard is subject to something along the lines of the following Means-End Coherence requirement:

\section{Means-End Coherence:}

Rationality requires that [if one intends $X$, and believes that one will achieve $X$ only if one intends $\mathrm{Y}$, then one intends $\mathrm{Y}]$.

According to Means-End Coherence, rationality requires that if Richard intends to return the books (which, according to the all-out intention analysis, he does) and believes that he will achieve his goal of returning the books only if he intends to pack them in his bag (which, as stipulated in our example, he does), then he must intend to pack the books in his bag. Since deciding not to pack the books would be inconsistent with intending to pack them, this explains why Richard would be irrational if he decided not to pack the books.

Unfortunately, the all-out intention analysis suffers from at least one fatal weakness: it is unable to preserve the intuition that Richard is not being irrational when he adopts the dual plans. Given that returning the books to the library precludes renewing the books online, it would be irrational for Richard to all-out intend to bring

\footnotetext{
${ }^{3}$ I will henceforth leave the "so long as he continues to have the dual plans" qualification implicit.
} 
about both ends. Richard would be violating something along the lines of the following consistency principle:

Intention Consistency:

Rationality requires that [if one intends $X$, and believes that $X$ entails $\neg Y$, then one not intend $\mathrm{Y}]$.

Hence, if we were to adopt the all-out intention analysis, we would find ourselves unable to preserve the intuition that Richard is not being irrational.

The lesson to be learned from the failure of the all-out intention analysis is that a satisfactory account of dual-plan cases must balance two goals: it must explain why it would be irrational for Richard to decide not to pack his books or laptop, while also preserving the intuition that Richard is not being irrational for having a pair of mutually exclusive plans. These goals seem to pull in opposite directions. Saying that Richard would be irrational if he decided not to pack his books or laptop pushes us towards saying that his dual plans represent competing intentions. However, saying that Richard is not being irrational by having the dual plans pushes us towards saying that his dual plans are not competing intentions after all.

\section{The Disjunctive Intention Analysis}

A second way of making sense of OVERDUE BOOKS is by claiming that Richard has a single intention with the disjunctive content: "return or renew the books". Call this the disjunctive intention analysis. If we let [Return] stand for "return the books to the library" and [Renew] stand for "renew the books online when one gets home", then the content of Richard's intention, according to the disjunctive analysis, may be represented thus:

(A) Intend ([Return] $\vee[$ Renew $])$

The strength of the disjunctive intention analysis is that it preserves the intuition that Richard is not guilty of any irrationality. Just as it is rationally permissible to believe a disjunction in which the disjuncts are not compossible-e.g., $\mathbf{P} \vee \neg \mathbf{P}$ - it is rationally permissible to intend a disjunction-i.e., [Return] $\vee[$ Renew]-in which the disjuncts are not compossible. Thus, if we hold that Richard has a disjunctive intention to return or renew the books, the fact that returning the books precludes renewing the books does not entail any irrationality on Richard's part.

The main weakness of the disjunctive intention analysis is that it fails to preserve the intuition that Richard would be irrational if he decided not to pack his books or decided not to pack his laptop. According to Means-End Coherence, rationality requires that, insofar as Richard has the end of returning the books, and believes that achieving this end requires intending to pack the books in his bag, he intend to pack 
the books. But let us assume, for the sake of argument, that Richard has a disjunctive intention to return or renew the books. Packing the books is not necessary for satisfying the disjunctive intention. Hence, if he is rational, Richard will not believe that packing the books is necessary for satisfying the disjunctive end of returning or renewing them. Consequently, Means-End Coherence would fail to require that Richard intend to pack the books if he intends to return or renew the books. An analogous, but independent, argument can be advanced to show that Richard is not rationally required to pack his laptop. The upshot is that the disjunctive intention account fails to explain why Richard would be irrational if he decided not to pack the books or laptop.

\section{The Conditional Intention Analysis}

A third option for making sense of OVERDUE BOOKS would be to say that Richard has a conditional intention to renew the books. On this view, Richard has an all-out intention to return the books and a conditional intention to renew the books if he fails to return them. Call this the conditional intention analysis. One strength of the conditional intention analysis is that it preserves the intuition that Richard is not being irrational. According to the conditional intention analysis, Richard has the following two intentions:

(B) Intend ([Return])

(C) Intend ( $\neg[$ Return $] \supset[$ Renew $])$

Since there is no inconsistency between intentions (B) and (C), attributing (B) and (C) to Richard preserves the intuition that Richard is not being irrational.

Unfortunately, the conditional intentional analysis is subject to much the same objection as the disjunctive intention analysis. Given the logical equivalence ' $\neg \supset \mathrm{P} \equiv$ $\mathrm{P} \vee \mathrm{Q}^{\prime}$, it follows that $(\mathrm{C})$ is equivalent to:

\section{(A) Intend ([Return] $\vee[$ Renew $])$}

We are now back to the disjunctive account discussed earlier, except that Richard has an additional intention with the content [Return]. Hence, Richard has the following pair of intentions:

\section{(A) Intend ([Return] $\vee[$ Renew $])$}

(B) Intend ([Return])

The upshot is that we are unable to preserve the intuition that Richard would be irrational if he decided not to pack his laptop. There is no rational pressure on Richard to pack the laptop because the disjunction is already being made true by his intending 
the first disjunct. That is to say, the disjunctive intention, (A), is already being satisfied by (B), Richard's intention to return the books. It is therefore false that Richard believes that packing the laptop is necessary for returning or renewing the books, and (a fortiori) Richard does not believe that packing the laptop is necessary for returning the books (i.e., satisfying the first disjunct). We are therefore left without the theoretical resources necessary for explaining why it would be irrational for Richard to decide not to pack the laptop.

I do not take the three analyses of OVERDUE BOOKS just limned to be exhaustive. Indeed, in the next section, I will put forward my own analysis and I am sure there are others that can be given. My aim in the preceding discussion has been to convey some sense of the dialectical terrain that motivates Holton's partial intention analysis. The challenge that the partial intention analysis sets out to meet is that of explaining how it could both be true that Richard is not being irrational for having a pair of mutually exclusive plans while also preserving the idea that it would be irrational for Richard to decide not to pack his books or laptop.

\section{The Partial Intention Analysis}

We now turn our attention to Holton's proposed analysis of OVERDUE BOOKS, what I refer to as the partial intention analysis. According to Holton, a partial intention stands in the same relation to an all-out intention as a partial belief stands to an all-out belief. Let us therefore begin with Holton's definitions of an all-out belief and a partial belief:

\section{All-out Belief}

One all-out believes $\mathbf{P}$ iff one takes $\mathbf{P}$ as a live possibility and does not take $\neg \mathbf{P}$ as a live possibility.

\section{Partial Belief}

One partially believes $\mathbf{P}$ iff one takes $\mathbf{P}$ as a live possibility and takes $\neg \mathbf{P}$ as a live possibility. ${ }^{4}$

What distinguishes a partial belief from an all-out belief is that the former involves taking both $\mathbf{P}$ and $\neg \mathbf{P}$ as live possibilities. This means, according to Holton, that a partial belief in $\mathbf{P}$ is automatically accompanied by a partial belief in $\neg \mathbf{P}$. Holton aims to preserve this aspect of partial belief in his account of partial intentions. However, Holton observes that in the case of partial intentions, the second intention does not come for free, as it does in the case of belief. ${ }^{5}$ Instead, we must look to cases in which an agent has two competing plans to bring about some end, and intends the actions

\footnotetext{
${ }^{4}$ Holton (2008: 39)

${ }^{5}$ Holton (2008: 40-43).
} 
necessary for both. This leads Holton to define a partial intention as one that is accompanied by an alternative intention towards the same end:

\section{Partial Intention}

An intention to bring about $\mathbf{P}$ is partial iff it is designed to achieve a given end $\mathbf{E}$ and it is accompanied by one or more alternative intentions also designed to achieve E. ${ }^{6}$

One strength of the partial intention analysis is that it preserves the intuition that Richard is not being irrational when he adopts dual plans. Holton observes that we are warranted in concluding that Richard is being irrational only if we assume that partial intentions are to be held to the same consistency requirements as all-out beliefs. However, this would be to fail to treat like cases alike. Insofar as we are here attributing to Richard a pair of partial intentions, then his intentions should be held to the same consistency requirements as partial beliefs. Holton writes:

We do not require that partial beliefs be consistent, in the sense that everything that we partially believe must be compossible; so we should not require this of our partial intentions. Instead, we should require of our partial intentions at most the same kind of consistency that we require of our partial beliefs. ${ }^{7}$

Holton does not go on to elaborate, but I believe his point may be illustrated as follows: suppose one has a partial belief with a credence of 0.45 in $\mathbf{P}$. One is rationally permitted to have a partial belief with a credence of 0.55 in $\neg \mathbf{P}$, even though $\mathbf{P}$ and $\neg \mathbf{P}$ are not compossible. ${ }^{8}$ Hence, we do not require that everything an agent partially believes be compossible. A similar allowance, Holton insists, should be made for partial intentions. Hence, Richard may partially intend to both return and renew the books, despite the fact that both actions are not compossible. The upshot is that, insofar as Richard partially intends to return the books and partially intends to renew the books online, he is not being irrational.

A second strength of the partial intention analysis is that it appears to provide an explanation of why it would be irrational for Richard to decide not to pack his books and/or laptop. If we assume that partial intentions are governed by Means-End Coherence, then rationality requires that if Richard partially intends to return the books, and believes that packing the books is necessary for returning the books, then he intend to pack the books. ${ }^{9}$ An analogous point holds with regards to Richard's

\footnotetext{
${ }^{6}$ Holton (2008: 41).

${ }^{7}$ Holton (2008: 47).

${ }^{8}$ Indeed, according to the additivity axiom for credences (understood as probability functions), it would be irrational to intend $\mathbf{P}$ or $\neg \mathbf{P}$ to a degree less than or greater than the sum of the degree to which one intends $\mathbf{P}$ and one intends $\neg \mathbf{P}$. This means that one is not only rationally permitted to have a credence of 0.45 towards $\mathbf{P}$ if one's credence in $\neg \mathbf{P}$ is 0.55 . One is rationally required to do so.

${ }^{9}$ I should register that I have misgivings about the claim that partial intentions are subject to Means-End Coherence, given that they're not subject to Intention Consistency. Indeed, it seems to me that these two
} 
partial intention to renew the books online. If this is right, then the partial intention analysis is able to explain why Richard would be irrational if he decided not to pack his books or laptop. To do so would be to violate the Means-End Coherence requirement that governs partial intention.

\subsection{Holton's Non-Account "Account"}

One of the most distinctive features of Holton's account of partial intentions is that it requires that an agent have two or more psychologically-distinct attitudes. Holton thinks that conceiving of partial intentions in this way is necessary for preserving the parity between partial intentions and partial beliefs. But this seems to rest on the mistaken assumption that taking $\mathbf{P}$ and $\neg \mathbf{P}$ as live possibilities entails the adoption of two psychologically-distinct doxastic attitudes (one towards $\mathbf{P}$ and another towards $\neg \mathbf{P}$ ). But this is not necessarily the case. For example, I may partially believe that [I will get a promotion by year's end], owing to the fact that I have less than full confidence that I will get the promotion, without my having a second, psychologicallydistinct, doxastic attitude towards the proposition [I will not get a promotion by year's end]. Indeed, the proposition [I will not get a promotion by year's end] may not have even crossed my mind. In other words, saying that an agent who partially believes $\mathbf{P}$ takes both $\mathbf{P}$ and $\neg \mathbf{P}$ as live possibilities is to offer a formal, rather than psychological, characterization of partial belief; it is an attempt to capture a formal consequence of having an attitude that involves less than full credence in $\mathbf{P}$.

Once we register that the sense in which partially believing $\mathbf{P}$ entails partially believing $\neg \mathbf{P}$ is formal rather than psychological, the claim that partial beliefs involve a pair of doxastic attitudes can no longer serve as a basis for distinguishing between partial and all-out beliefs. This is because the formal point applies equally to all-out beliefs. Just as assigning a credence of 0.45 to $\mathbf{P}$ formally entails assigning a credence of 0.55 to $\neg \mathbf{P}$, assigning a credence of 1 to $\mathbf{P}$ formally entails assigning a credence of 0 to $\neg \mathbf{P}$. Put in non-credal terms, an all-out belief in $\mathbf{P}$ formally entails an all-out disbelief in $\neg \mathbf{P}$. Hence, if we take partial beliefs to necessarily involve two distinct doxastic attitudes (on purely formal grounds), then parity of reasoning demands that we do the same for all-out beliefs. The upshot is that the fact that partial beliefs entail the possession of two doxastic attitudes (one towards $\mathbf{P}$ and another towards $\neg \mathbf{P}$ ) cannot serve as a point of contrast between partial and all-out beliefs since the same is true of all-out beliefs. We therefore have no reason to assume that this should be a point of contrast between partial and all-out intentions. If partial intentions really stand to allout intention as partial belief stands to all-out belief, as Holton claims, then we should expect all-out intentions to also involve two psychologically distinct attitudes. Clearly, something has gone wrong with Holton's account.

My diagnosis of what goes wrong is that Holton's "account" of partial intention is not an account of partial intention at all, but rather the description of the kind of case an account of partial intention should be able to explain. To see why this is so, we may

norms stand and fall together, so that any attitude that is subject to the one requirement will be subject to the other. However, this is not a line of argument I will attempt to develop here. 
begin by observing that it is possible that an agent who partially believes $\mathbf{P}$ may have two distinct psychological attitudes (one towards $\mathbf{P}$ and another towards $\neg \mathbf{P}$ ). However, to conclude from this that we should define partial beliefs in terms of the possession of two doxastic attitudes would be to conflate explanans with explanandum. Consider: many theorists posit the existence of partial beliefs in order to explain phenomenon like the preface paradox, cases in which an agent rationally believes $\left(\mathbf{P}_{1}\right)$, believes $\left(\mathbf{P}_{2}\right), \ldots$. , believes $\left(\mathbf{P}_{100}\right)$ but does not believe $\left(\mathbf{P}_{1}, \mathbf{P}_{2}, \ldots ., \mathbf{P}_{100}\right)$. However, having a partial belief does not consist in the act of rationally believing $\left(\mathbf{P}_{1}\right)$, believing $\left(\mathbf{P}_{2}\right), \ldots$, believing $\left(\mathbf{P}_{100}\right)$ and failing to believe $\left(\mathbf{P}_{1}, \mathbf{P}_{2}, \ldots, \mathbf{P}_{100}\right)$. Rather the existence of partial beliefs is posited in order to explain how it is possible to rationally believe $\left(\mathbf{P}_{1}\right)$, believe $\left(\mathbf{P}_{2}\right), \ldots$, believe $\left(\mathbf{P}_{100}\right)$, without also believing $\left(\mathbf{P}_{1}, \mathbf{P}_{2}, \ldots, \mathbf{P}_{100}\right)$. Partial belief (i.e., the explanans) is what allows us to make sense of how the preface paradox (i.e., the explanandum) is possible. But having a partial belief does not require actually being in a preface paradox. ${ }^{10}$ Similarly, we may appeal to the notion of a partial belief to explain how it may be rationally permissible for an agent to have competing doxastic attitudes. However, having a partial belief does not consist in rationally having competing doxastic attitudes.

Analogously, partial intentions are not to be identified with cases in which it is rationally permissible for an agent to have competing intentions geared towards the same end. Insofar as partial intentions exist, they should be what explain this possibility. If this is right, then Holton's definition of a partial intention is not a definition at all, but rather the description of the kind of case we would need to posit the existence of a partial intention to explain. At best, what Holton offers is a potential explanandum, not an explanans. There is simply no account of partial intentions on offer in Holton's paper.

\section{The Intending to Try Analysis}

I submit that we may arrive at a satisfactory analysis of OVERDUE BOOKS by holding that Richard has a single intention to prevent his library privileges from being suspended and that he intends to try to achieve this goal in two different ways: by either returning the books after the seminar or renewing them online when he gets home. ${ }^{11}$ On the present suggestion, it is the fact that Richard intends to try to return the books, and believes that packing the books is necessary for trying to return the books, that explains why it would be irrational for Richard to decide not to pack the books, and it is the fact that Richard intends to try to renew the books, and believes that packing his laptop is necessary for trying to renew the books, that explains why it

\footnotetext{
${ }^{10} \mathrm{I}$ wish to remain neutral on the question of whether the preface paradox is best explained in terms of partial beliefs. My claim, here, is simply that a partial belief should not be identified with the phenomenon it is employed to explain. Presumably, this point also applies to would-be partial intentions. ${ }^{11}$ Michael Bratman (1984) employs a similar strategy to deal with his video game case. I add an important qualification in the final section of this paper.
} 
would be irrational for Richard to decide not to pack his laptop. Hence, the intending to try analysis is able to preserve the intuition that Richard would be irrational if he decided not to pack the books or laptop. Moreover, even if returning the books precludes renewing the books online, trying to return the books does not preclude trying to renew the books. Indeed, the acts of packing the books and laptop are instances of trying to return and renew the books, respectively, and these are obviously compossible states of affairs. Hence, according to the intending to try analysis, Richard does not violate Intention Consistency. It therefore preserves the intuition that Richard is not being irrational when he adopts the dual plans.

One worry that may arise with respect to the present account is that the intention to try is not strong enough to ground Means-End Coherence. To this end, it may be argued that even if Richard believes that packing the books is necessary for returning the books, he need not believe that doing so is necessary for intending to try to return books. The efficacy of this argument will depend on the conception of trying we are employing. Moreover, I believe that there is an intuitive conception of trying according to which intending to try is governed by Means-End Coherence. I shall provide a brief sketch of just such a conception at present.

Consider an agent, Emma, who is at an auction and is in the process of bidding on a particularly desirable vase. Emma has $\$ 500$ on her. This means that it is within Emma's power to bid on the vase up until the $\$ 500$ mark. ${ }^{12}$ As the auctioneer announces a new price for the vase $-\$ 150 \ldots \$ 250 \ldots . \$ 350 \ldots$ and so on - what Emma believes is necessary for purchasing the vase is being constantly updated. When the starting price of $\$ 150$ is announced, Emma comes to believe that she must bid at least $\$ 150$ to purchase the vase. Intuitively, if she refrains from bidding $\$ 150$ (i.e., doing what she believes to be necessary for purchasing the vase), then she does not count as trying to purchase the vase. Let us assume that Emma continues to bid up until the $\$ 350$ mark. However, once the announced price of the vase climbs above $\$ 350$, she stops bidding. At this point, it seems natural to say that Emma has stopped trying to purchase the vase. Moreover, a natural description of the entire scenario seems to be that Emma tried to purchase the vase, but that (at a certain point) she stopped trying. At which point did she stop trying? She stopped trying at the point at which she stopped bidding-i.e., the point at which she stopped doing what she believed to be necessary for purchasing the vase.

What the above example is meant to illustrate is that there is an intuitive notion of trying according to which one only counts as trying to $X$ at some time, $T$, if one does everything one can at $\mathrm{T}$ to $\mathrm{X}$ (i.e., one does everything within one's power and that one believes to be necessary for X-ing). ${ }^{13}$ Such a conception of trying is strong enough to ground Means-End Coherence. In our example, if Emma believes that bidding $\$ 250$ at

\footnotetext{
${ }^{12}$ According to the conception of trying I defend, trying only requires that one do what one truly believes is within one's power. On this view, one may count as trying to $\mathrm{X}$ at $\mathrm{T}$ even though one fails to do something one believes to be necessary to X at T, so long as that thing is either outside of one's power or one believes it is outside one's power. Henceforth, I will leave this additional qualification implicit.

${ }^{13}$ For a defence of the idea that trying to X entails doing everything one can to X, see Hornsby (2010).
} 
time $T_{2}$ is necessary for purchasing the vase, then she only counts as trying to purchase the vase at $T_{2}$ if she does in fact bid $\$ 250$ at $T_{2}$. In short, trying to $X$ at some time $T_{2}$ requires doing everything she can to $\mathrm{X}$ at $\mathrm{T}_{2}$. Means-End Coherence, when applied to Emma, comes to the following claim:

\section{Means-End Coherence (Emma):}

Rationality requires that [if Emma intends to try to purchase the vase, and believes that bidding $\$ 250$ at time $T_{2}$ is necessary for trying to purchase the vase, then she must intend to bid $\$ 250$ at time $\mathrm{T}_{2}$ ].

Given that trying to $X$ at some time $T$ requires doing everything one can to $X$ at $T$, it follows that intending to try to $X$ makes the same Means-End Coherence demands as intending to $X$.

\section{Holton's Objections to the Intending to Try Analysis}

Holton anticipates and responds to the intending to try analysis as follows:

We surely would not say that you intend to try to take the library books back; it is not as though the library is currently under siege and you are sceptical about your abilities to get through the defences. No-if you get home and find to your annoyance that the books are still in your bag, it will not be true that you even tried to take them back. ${ }^{14}$

Unsurprisingly, I do not find Holton's objections to the intending to try analysis convincing. Two independent lines of argument may be gleaned from the preceding passage. First, Holton protests that Richard cannot be said to have the intention to try given that he faced no external environmental obstacles - such as overcoming a library siege - that would prompt him to question his ability to return the books. But why should the potential obstacles Richard faces be restricted to features of his external environment? After all, Richard's tendency to forget to do things after department seminars is as much an obstacle as any to his returning the library books. Hence, the restriction to environmental obstacles seems ad hoc.

Holton's second rationale for thinking that Richard does not intend to try is that if Richard were to arrive home only to recognize that he had forgotten to return the books, it would be inaccurate to say that he ever tried to return them. Holton takes it to follow from this that Richard never intended to try to return the books. Holton's argument presupposes that intending to try entails actually trying. But this is not plausible. If I were to suffer a stroke between my decision to kick a ball and my actually kicking it, it would not follow that I never had an intention to kick the ball. I form the intention to do something at the point at which I resolve to do it, not at the point at which I begin doing it. Likewise, I form the intention to try at the point at

\footnotetext{
${ }^{14}$ Holton (2008: 29).
} 
which I resolve to try, not the point at which I actually begin trying. The mistake Holton seems to make is that he assumes that because trying requires putting fort some kind of effort that the same is also true of intending to try. But intending to try is a case of intending, not a case of trying. Like all other cases of intending, it does not require that one actually do what one intends to do (or even that one put fort any effort towards achieving what one intends to do) in order to count as intending to do it. In sum, the fact that Richard forgets to try to return the books no more entails that he never intended to try to return the books than someone's forgetting to perform an action entails that they never intended to perform it.

The takeaway of the preceding discussion is that Holton's conclusion that we can only make sense of OVERDUE BOOKS by attributing a partial intention to Richard is unwarranted. We can also make sense of OVERDUE BOOKS by saying that Richard has an all-out intention to try to return the books. Consequently, the traditional conception of intentions already has the resources necessary to make sense of OVERDUE BOOKS and there is therefore no need to posit the existence of partial intentions in order to make sense of dual-plan cases.

\section{References}

Bratman, Michael. (1984). Two Faces of Intention. The Philosophical Review, 93 (3): 375-405. Holton, Richard. (2008). Partial Belief, Partial Intention. Mind. 117 (465): 27-58.

Hornsby, Jennifer. (2010). Trying to Act. In T. O'Connor, and C. Sandis, (Eds.), A Companion to the Philosophy of Action. (pp. 18-25). Malden, MA: Wiley Blackwell. 